\title{
Phase II clinical study of eribulin monotherapy in Japanese patients with metastatic breast cancer who had well-defined taxane resistance
}

\author{
Kenichi Inoue $^{1}$ Tsuyoshi Saito ${ }^{2} \cdot$ Katsuhiko Okubo $^{3} \cdot$ Kei Kimizuka $^{4}$. \\ Hirofumi Yamada ${ }^{5} \cdot$ Takashi Sakurai $^{6}$ - Kazuo Ishizuna ${ }^{7} \cdot$ Satoshi Hata $^{8}$. \\ Toshihiro Kai ${ }^{9}$ Masafumi Kurosumi ${ }^{10}$
}

Received: 23 March 2016/ Accepted: 19 April 2016/Published online: 28 April 2016

(C) The Author(s) 2016. This article is published with open access at Springerlink.com

\begin{abstract}
No clinical evidence on the efficacy and safety of eribulin monotherapy has been obtained by a prospective clinical study in patients with metastatic breast cancer (MBC) who had well-defined taxane resistance. The present Phase II, multicenter, single-arm, open-label study aimed to obtain the evidence. Japanese female patients, aged 33-74 years who had the metastasis of taxane-resistant and histopathologically confirmed breast cancer, received eribulin mesylate $1.4 \mathrm{mg} / \mathrm{m}^{2}$ (equivalent to eribulin $1.23 \mathrm{mg} / \mathrm{m}^{2}$ [expressed as free base]) as a 2 - to 5 -min intravenous infusion on days 1 and 8 of each 21-day cycle. The primary endpoint was the clinical benefit rate (CBR) [complete response (CR), partial response (PR), and
\end{abstract}

Kenichi Inoue

ino.bad.ken@gmail.com

1 Division of Breast Oncology, Saitama Cancer Center, 780 Komuro, Ina-machi, Kita-adachi-gun, Saitama 362-0806, Japan

2 Department of Breast Surgery, Saitama Red Cross Hospital, Saitama, Japan

3 Department of Breast Unit, Toda Central General Hospital, Saitama, Japan

4 Department of Breast Surgery, Kasukabe Municipal Hospital, Saitama, Japan

5 Department of Surgery, Sekishindo Hospital, Saitama, Japan

6 Division of Surgery, JCHO Saitama Medical Center, Saitama, Japan

7 Breast Center, Dokkyo Medical University Koshigaya Hospital, Saitama, Japan

8 Breast Center, Mitsui Hospital, Saitama, Japan

9 Shintoshin Ladies' Mammo Clinic, Saitama, Japan

10 Department of Pathology, Saitama Cancer Center, Saitama, Japan long-term stable disease (LSD) $\geq 24$ weeks]. A total of 51 patients underwent chemotherapy cycles (median 4; range 1-42 cycles). The CBR was $39.2 \%$ (CR $2.0 \%$; PR $23.5 \%$; and LSD $13.7 \%$ ), and the rate of progressive disease was $49.0 \%$. The median progression-free survival and the median overall survival were 3.6 months [95\% confidence interval (CI) 2.6-4.6 months] and 11.7 months (95\% CI 9.2-14.2 months), respectively. Grade 3 or greater adverse events were leukopenia $(23.5 \%)$, neutropenia $(35.3 \%)$, anemia (5.9\%), and febrile neutropenia $(7.8 \%)$. The incidences of grade 3 and 4 peripheral sensory neuropathy were 2.0 and $0 \%$, respectively. Eribulin showed a clinically manageable tolerability profile by dose adjustments or symptomatic treatment. Eribulin was effective and well tolerated in heavily pretreated patients with MBC who had well-defined taxane resistance, thus providing a potential therapeutic option in the clinical settings.

Keywords Eribulin mesylate - Metastatic breast cancer . Taxane resistance $\cdot$ Estrogen receptor $\cdot$ Human epidermal growth factor receptor 2-negative - Triple-negative

\section{Introduction}

Breast cancer is the most common cancer in American women, with estimated new cases and deaths of 231,840 (28.6\% of all new cancers in women) and 40,290 (14.5\% of all cancer deaths in women), respectively, for year 2015 [1]. Approximately $5-10 \%$ of patients with breast cancer present metastasis at diagnosis, and up to 30 and $70 \%$ of node-negative and -positive breast cancers will relapse, respectively [2]. In Japanese women, on the other hand, the estimated number of new cases and deaths were 86,700 
(22.8\% of all new cases in women) and 13,400 (9.0\% of all cancer deaths in women), respectively, for year 2014 . Breast cancer is the fifth most common malignancy causing cancer deaths, preceded by colon, lung, stomach, and pancreatic cancers in 2013 [3].

Chemotherapy constitutes a beneficial therapeutic armamentarium for patients with metastatic breast cancer (MBC) although the complete cure of the disease is difficult to attain, and anthracyclines and taxanes-two most active classes of cytotoxic agents that are commonly used for the treatment of breast cancer-are preferred as single agents for recurrent or metastatic breast cancer [4]. However, lifetime exposure to the former is restricted due to their cardiotoxicity, myelosuppression, and alopecia. On the other hand, the latter provokes alopecia, peripheral neuropathy, and other serious adverse events. Furthermore, the emergence of resistance to anthracyclines and taxanes has become a major clinical obstacle [5].

Eribulin, which is a non-taxane microtubule dynamics inhibitor belonging to the halichondrin class of antineoplastic agents [6], has a unique end-poisoning mechanism that results predominantly in the inhibition of microtubule growth with no or little effect on shortening [7, 8]. Consequently, eribulin exerts its cytotoxicity by suppressing microtubule growth and sequestering tubulins, eventually causing $\mathrm{G}_{2}-\mathrm{M}$ cell cycle arrest and apoptosis [9-11]. Eribulin has shown antitumor activity for a number of human cancer cell lines and xenografts with a variety of therapeutic indexes [12]. In addition to its pharmacological potency superior to other agents (e.g., paclitaxel and vinblastine), eribulin has potent activity against paclitaxelresistant human cancer cell lines in vitro [13]. Apart from its cytotoxicity, eribulin induces the remodeling of tumor vasculature through a novel antivascular activity and a reversing effect on the epithelial-mesenchymal transition of cancer cells - a key process for metastatic promotion in cancer, thus inhibiting metastasis [14-19]. This may also contribute to the extension of survival of patients with MBC.

In prior Phase II and III clinical studies of eribulin monotherapy, the drug has shown antitumor activity and a survival benefit for patients with MBC who had previously undergone anthracycline- or taxane-based chemotherapy regimens [20-26]. Especially in a Phase III open-label randomized clinical study of eribulin (EMBRACE) [25], furthermore, eribulin monotherapy showed a significant and clinically meaningful improvement in the overall survival (OS) of patients with MBC compared to treatment of physician's choice (TPC) in heavily pretreated patients with MBC. In 2010, consequently, the Food and Drug Administration approved eribulin mesylate as third-line treatment for $\mathrm{MBC}$ refractory to anthracyclines and taxanes [27]. By contrast, eribulin is approved as first or subsequent line therapy for the treatment of patients with MBC in Japan. As described above, prior clinical studies have examined the efficacy and safety of eribulin in patients with MBC who were previously treated with taxanes. However, no clinical evidence about these features of eribulin has been obtained in MBC patients who had welldefined taxane resistance. Therefore, we conducted the present study to obtain the evidence.

\section{Methods}

\section{Study design}

A Phase II, multicenter, single-arm, open-label clinical study (University Hospital Medical Information Network identifier: 000006965) was conducted at eight medical institutions in Japan and enrolled Japanese female patients with MBC who were found to have well-defined taxane resistance. The administration of colony-stimulating factors (G-CSFs) was allowed according to the Japanese Society of Clinical Oncology guidelines.

\section{Patients}

Female patients were considered eligible when meeting all of the following criteria: women aged 20-74 years with histopathologically confirmed breast cancer; prior chemotherapy regimens with taxanes and/or anthracyclines; Eastern Cooperative Oncology Group (ECOG) performance status: 0-2; lesions measurable by computed tomography or magnetic resonance imaging at least in one dimension; conserved functions of principle organs (bone marrow, liver, kidney, and lung)—neutrophil count: $\geq 1500 / \mu \mathrm{L} ;$ platelet count: $\geq 100,000 / \mu \mathrm{L}$; hemoglobin concentration: $\geq 8.0 \mathrm{~g} / \mathrm{dL}$; aspartate aminotransferase (AST) and alanine aminotransferase (ALT): $\leq 2.5$-fold the upper limit of normal (ULN) or $\leq 5$.0-fold the ULN in patients with hepatic metastasis; total bilirubin: $\leq 1.5$-fold the ULN; and serum creatinine concentration: $\leq 1.5$-fold the ULN; and written informed consent. A woman with MBC, who was already under chemotherapy, was considered to present well-defined taxane resistance when falling under either of the following cases: (1) breast cancer recurred during taxane treatment or within 1 year after the last administration when undergoing neo- or adjuvant chemotherapy with taxanes and 2) the tumor progressed (from CR/PR/SD to PD or PD) during taxane treatment.

Women were excluded when falling under any of the following criteria: systemic infection involving fever $\left(\geq 38^{\circ} \mathrm{C}\right)$; a large volume of pleural fluid, ascites, or pericardial fluid requiring drainage; brain metastasis with clinical symptoms; serious complications including heart 
disease (e.g., poorly controlled ischemic disease and arrhythmias excluding left ventricular hypertrophy associated with hypertension, mild left ventricular load, and mild right bundle branch block), myocardial infarction within previous 6 months, hepatic cirrhosis, interstitial pneumonia, pulmonary fibrosis, and bleeding tendency; active double cancer; overexpression of the human epidermal growth factor receptor type 2 (HER2) at the primary or metastatic lesion as either $(3+)$ by immunohistochemistry or $(+)$ by fluorescence in situ hybridization (FISH); pregnancy, breast-feeding, or women with childbearing potential; and ineligibility for the study.

Patients underwent study treatment until disease progression, unacceptable toxicity, consent withdrawal, or investigator's discretion to discontinue the treatment. All patients provided written informed consent before enrollment. The study was conducted in accordance with the Declaration of Helsinki, Good Clinical Practice, and local ethical and legal requirements. The study protocol was approved by the Institutional or Central Ethics Committee.

\section{Treatment}

Eribulin mesylate $1.4 \mathrm{mg} / \mathrm{m}^{2}$ (equivalent to eribulin $1.23 \mathrm{mg} / \mathrm{m}^{2}$ [expressed as free base]) was administered as a 2 - to 5-min intravenous infusion on days 1 and 8 of each 21-day cycle. Successive dose reductions to 1.1 and $0.7 \mathrm{mg} / \mathrm{m}^{2}$ were permitted at the investigator's discretion or to manage the following events: grade 3 or greater febrile neutropenia; grade 3 or greater neutropenia $(<1000 /$ $\mu \mathrm{L})$ requiring antibiotic treatment; grade 4 thrombocytopenia $(<25,000 / \mu \mathrm{L})$; grade 3 or greater nonhematologic toxicities excluding nausea, vomiting, anorexia, and laboratory abnormalities without clinical symptoms; and administration on day 8 of the cycle was omitted because grade 3 or greater neutropenia $(<1000 / \mu \mathrm{L})$ or thrombocytopenia $(<50,000 / \mu \mathrm{L})$ occurred. The second or subsequent cycle was postponed for a maximum of 2 weeks (day 36 of the previous cycle) in the event that at least one of the following criteria for next cycle initiation was unmet: neutrophil count: $\geq 1000 / \mu \mathrm{L}$; platelet count: $\geq 75,000 / \mu \mathrm{L}$; AST or ALT: $\leq 2.5$ fold the ULN; total bilirubin: $\leq 1.5$-fold the ULN; serum creatinine: $\leq 1.5$-fold the ULN; and nonhematologic toxicities: grade 2 or lower (excluding those caused by the disease and laboratory abnormalities without clinical symptoms). The dose delay or interruption was resumed after confirming that the criteria were met. Grade 3 or 4 adverse events (AEs) were managed by dose modifications (interruptions, delays, or reductions).

In principle, concomitant treatment for concurrent underlying disease was not restricted. However, the following concurrent or adjunctive therapy was not permitted: other anticancer treatments (e.g., immunotherapy, chemotherapy, and surgery); prophylactic administration of G-CSF; and other investigational drugs. Symptomatic treatment with G-CSFs was permitted for grade 4 neutropenia and grade 3 febrile neutropenia.

\section{Assessments}

\section{Efficacy}

Tumor lesions and markers were monitored at screening or day 1 and every 8 weeks thereafter. Subsequent monitoring could be rescheduled when a change in disease status was suspected. Tumor response was assessed according to Response Evaluation Criteria in Solid Tumors [28] at screening, week $8(+2$ weeks) after the day of first administration, and every 8 weeks ( \pm 2 weeks) after the day of previous observation of the tumor lesion. Tumor responses were categorized as follows: complete response (CR); partial response (PR); progressive disease (PD); stable disease (SD); and not evaluable (NE). CR and PR required two or more successive confirmations at 4-week or more intervals. The clinical benefit rate [CBR: $\mathrm{CR}+\mathrm{PR}+$ long-term SD (LSD: $S D \geq 24$ weeks)], the overall response rate (ORR: $\mathrm{CR}+\mathrm{PR}$ ), and the disease control rate (DCR: $\mathrm{CR}+\mathrm{PR}+\mathrm{SD}$ ) were calculated. Progression-free survival (PFS) was defined as the span from enrollment to the earliest date of disease progression, death, or censoring. Overall survival (OS) was defined as the span from enrollment to death or to the date of censoring. The efficacy and safety evaluation panel reviewed the efficacy and safety data on the investigator-assessed patients.

\section{Study endpoints}

The primary endpoint was the CBR, and the secondary endpoints were PFS, OS, and safety.

\section{Safety}

AEs were recorded and graded according to the Common Terminology Criteria for Adverse Events Japanese version 4.0, and coded according to the Medical Dictionary for Regulatory Activities, Japanese version (MedDRA/J).

Vital signs and ECOG performance status were assessed; laboratory tests (hematology and blood biochemistry) and 12-lead electrocardiography at rest were conducted before recruitment and at the time of each visit, discontinuation, and completion.

\section{Statistical analyses}

PFS and the ORR (median with $95 \%$ confidence interval [CI]) were calculated using Kaplan-Meier estimates. 
Safety data were evaluated using descriptive statistics. Sample size was estimated to be 52 based on previous clinical studies: in a Phase II study [21], the independently reviewed CBR was $17.1 \%$ (95\% CI 12.8-22.1\%) and the investigator-reviewed CBR was $19.7 \% \quad(95 \%$ CI 15.1-25.0\%); in a Phase III study [25], these CBRs were $23.0 \%$ (95\% CI $18.9-26.7 \%$ ) and $28.0 \%$ (95\% CI 23.8-32.1\%), respectively. We assumed that third-line therapy would produce antitumor activity comparable to that described in these previous studies and established an expected CBR of $23 \%$ and a threshold CBR of $10 \%$, with $80 \%$ power at a type I error of $5 \%$ (two-sided alpha). These assumptions produced 52 samples for the detection of tumor response. SPSS version 19 (IBM, Armonk, NY) was used to make all statistical analyses.

\section{Results}

\section{Patients}

A total of 53 patients were recruited at eight institutions in Japan between February 2012 and November 2014, two of whom were subsequently excluded from the study because of not meeting the key inclusion criteria; consequently, 51 were enrolled. The baseline demographic and clinical characteristics of the patients are shown in Table 1. The median age was 55.0 years (range 33.9-74.4 years), 25 $(49.0 \%)$ had an ECOG performance status of 0,31 $(60.8 \%)$ had estrogen receptor (ER)-positive breast cancer, 19 (37.3\%) had triple-negative breast cancer, 46 (90.2 \%) had undergone chemotherapy after recurrence with a median of 2 regimens (range $0-7), 25(49.0 \%$ ) had four or more metastases-predominantly in the bone, lung, and liver, and $37(72.5 \%)$ had grade 1 or greater peripheral sensory neuropathy.

\section{Study drug exposure}

The median of cycles delivered was 4 (range 1-42 cycles). Among 51 patients treated, 13 (25.5\%), 18 (35.3\%), and 11 $(21.6 \%)$ experienced dose interruptions, delays, and reductions during cycle 1 , respectively, primarily as a result of neutropenia. One $(2.0 \%)$ of the patients discontinued eribulin administration who had a cerebrovascular accident. The median of relative dose intensity (RDI) was $85.6 \%$ (range $31.0-101.3 \%)$. Four patients $(7.8 \%)$ received G-CSFs for the treatment of grade 3 febrile neutropenia.

\section{Efficacy}

The following variables for efficacy were obtained (Table 2): the CBR was $39.2 \%$ (95\% CI 25.8-53.9\%),
Table 1 Baseline demographic and clinical characteristics of patients

\begin{tabular}{ll}
\hline Characteristics & $\begin{array}{l}N=51 \\
n \text { (percentage) }\end{array}$ \\
\hline Age, years & \\
Median & 55.0 \\
Range & $33.9-74.4$ \\
ECOG performance status & \\
0 & $25(49.0 \%)$ \\
1 & $22(43.1 \%)$ \\
2 & $4(7.8 \%)$ \\
Hormone receptor status & \\
ER-positive & $31(60.8 \%)$ \\
Triple-negative (ER, PgR, HER2) & $19(37.3 \%)$ \\
Unknown & $1(2.0 \%)$ \\
Prior treatments & \\
Neoadjuvant chemotherapy & $20(39.2 \%)$ \\
Adjuvant chemotherapy & $20(39.2 \%)$ \\
Chemotherapy after recurrence & $46(90.2 \%)$
\end{tabular}

Number of prior chemotherapy regimens after recurrence 0

$5(9.8 \%)$

$1 \quad 8(15.7 \%)$

$2215(29.4 \%)$

$3 \quad 10(19.6 \%)$

$4 \quad 4(7.8 \%)$

$\geq 5$

Median 2

Range

$0-7$

Prior chemotherapy agent

Anthracycline $29(56.9 \%)$

Paclitaxel $42(82.4 \%)$

Docetaxel $8(15.7 \%)$

Paclitaxel and docetaxel $1(2.0 \%)$

Capecitabine/TS1 $37(72.5 \%)$

Vinorelbine $\quad 5(9.8 \%)$

Gemcitabine $\quad 8(15.7 \%)$

Site of metastasis

Bone $28(54.9 \%)$

Lung $24(47.1 \%)$

Liver $25(49.0 \%)$

Distal/regional lymph node 20/18 (39.2/35.3\%)

Local lesion $\quad 15(29.4 \%)$

Pleura $10(19.6 \%)$

Skin $\quad 8(15.7 \%)$

Brain $3(5.8 \%)$

Number of metastases

$1 \quad 5(9.8 \%)$

$2 \quad 7(13.7 \%)$

$3 \quad 14(27.5 \%)$

$\geq 4 \quad 25(49.0 \%)$

ECOG Eastern Cooperative Oncology Group, ER estrogen receptor, $P g R$ progesterone receptor, HER2 human epidermal growth factor receptor 2 
and the median ORR was $25.5 \%$ (95 \% CI 14.3-39.6\%). However, six of enrolled patients were found to have not received an anthracycline: two patients each in those who presented PR, LSD, and PD. After excluding these six patients from the assessment of efficacy, the following variables for efficacy were obtained: the CBR was $35.6 \%$ (95\% CI 21.9-51.2\%), and the median ORR was $24.4 \%$ (95 \% CI 12.9-39.5 \%). The Kaplan-Meier curves for PFS and OS are shown in Fig. 1. The median PFS was 3.6 months (95\% CI 2.6-4.6 months) and the median OS was 11.7 months (95\% CI 9.2-14.2 months). Percent changes in metastatic tumor size (total sum of the longest single dimension for measurable target lesions) from baseline to the maximal tumor shrinkage regarding best overall responses in the overall, liver, and lung are shown in Fig. 2; eribulin caused tumor shrinkage in the target organs that were examined (e.g., the liver and lung).

The CBRs were comparable between ER-positive and triple-negative patients (Table 3). Eribulin showed efficacy (CBR: $\geq 40 \%$ ) in the major organs of metastasis, e.g., lung and liver (Table 4). The rate of best overall response in patients who had undergone paclitaxel treatment was as high as $35.7 \%$ in the CBR (Table 5). Among the patients examined, the CBR was highest in patients whose best overall response was qualified from SD to PD (Table 6).

\section{Safety}

All patients experienced treatment-related adverse events (TRAEs), but eribulin showed a clinically manageable tolerability profile by dose modifications or symptomatic treatment. One patient suffered from a cerebrovascular accident about whom causality with eribulin could not be

Table 2 Best overall responses

\begin{tabular}{llr}
\hline & $n$ & $\%$ \\
\hline CR & 1 & 2.0 \\
PR & 12 & 23.5 \\
SD & 5 & 9.8 \\
LSD & 7 & 13.7 \\
PD & 25 & 49.0 \\
NE & 1 & 2.0 \\
CBR (CR + PR + LSD) & 20 & 39.2 \\
$95 \%$ CI & $25.8-53.9$ & \\
ORR (CR + PR) & 13 & 25.5 \\
$95 \%$ CI & $14.3-39.6$ & \\
DCR (CR + PR + SD) & 25 & 49.0 \\
$95 \%$ CI & $34.8-63.4$ & \\
\hline
\end{tabular}

$C R$ complete response, $P R$ partial response, $S D$ stable disease, $L S D$ long-term stable disease $\geq 24$ weeks, $P D$ progressive disease, $N E$ not evaluable, $C I$ confidence interval
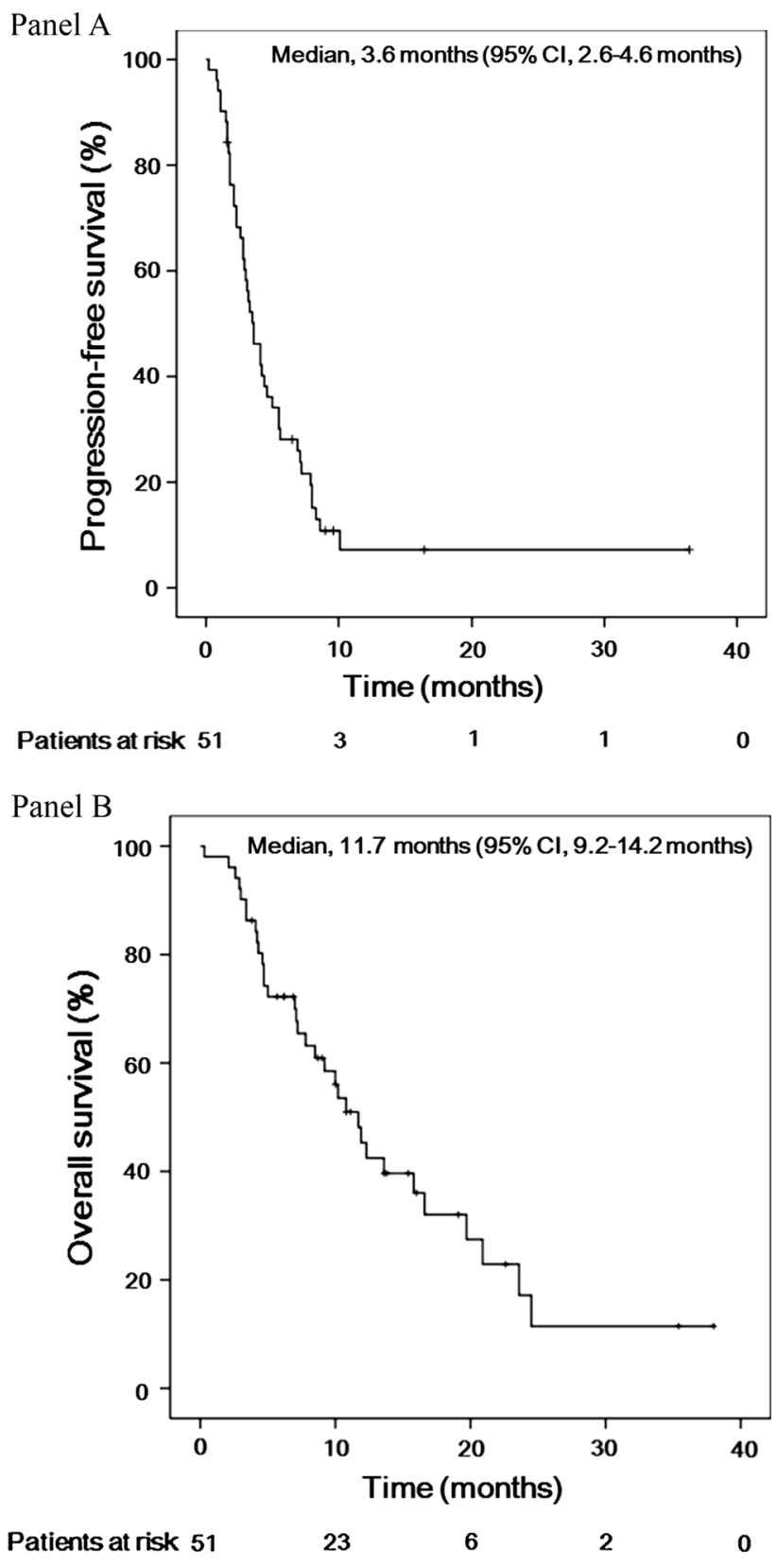

Fig. 1 Kaplan-Meier curves for progression-free survival (a) and overall survival (b)

ruled out, which led to the discontinuation of eribulin administration. However, no death occurred during the study period.

The most common TRAEs were neutropenia (35.3\%), leukopenia $(33.3 \%)$, and anemia $(29.4 \%)$ among hematologic AEs and were oral mucositis, alopecia, AST increased, fatigue, constipation, anorexia, and peripheral motor neuropathy (13.7 \% each) among nonhematologic AEs (Table 7). The grade 3 TRAEs were leukopenia $(19.6 \%)$, neutropenia (17.6\%), febrile neutropenia $(7.8 \%)$, and anemia $(5.9 \%)$. Neutropenia was managed by 
Fig. 2 Waterfall plots of percent changes in metastatic tumor size (total sum of the longest single dimension for measurable target lesions) from baseline to the maximal tumor shrinkage regarding best overall responses: a overall, b liver, and c lung. $C R$ complete response, $P R$ partial response, $S D$ stable disease, $P D$ progressive disease, $L S D$ long-term stable disease

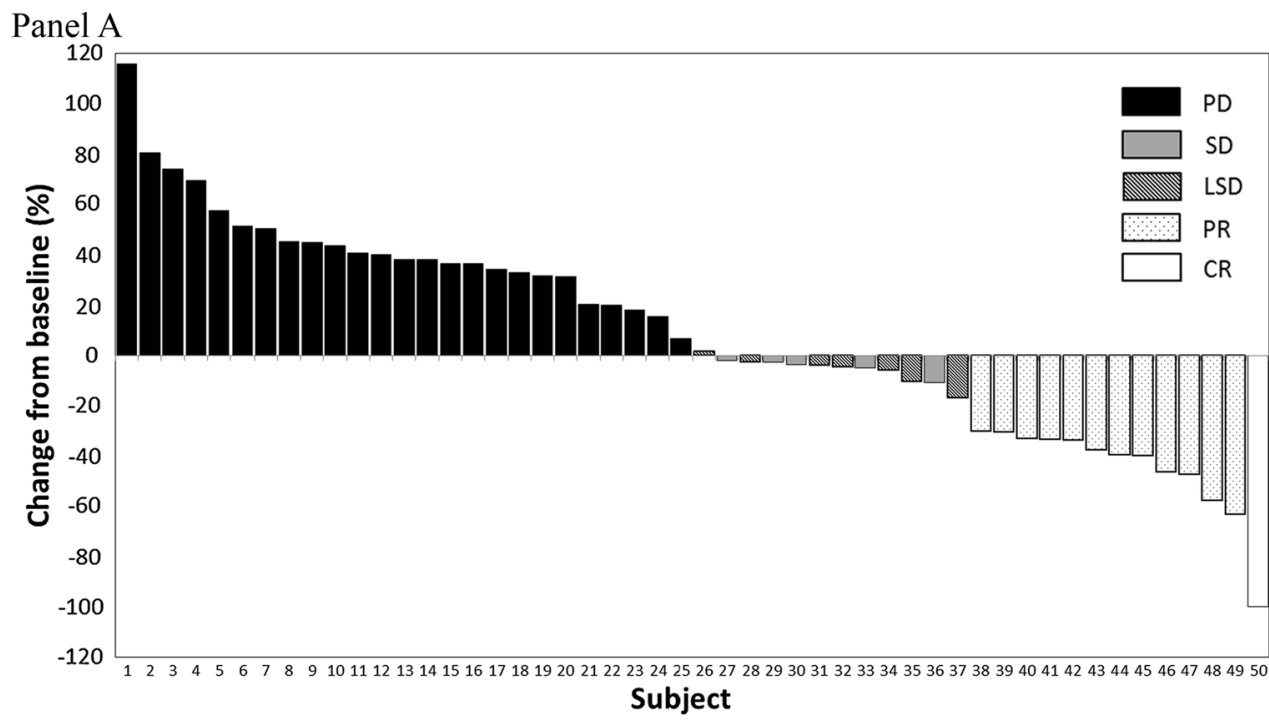

Panel B

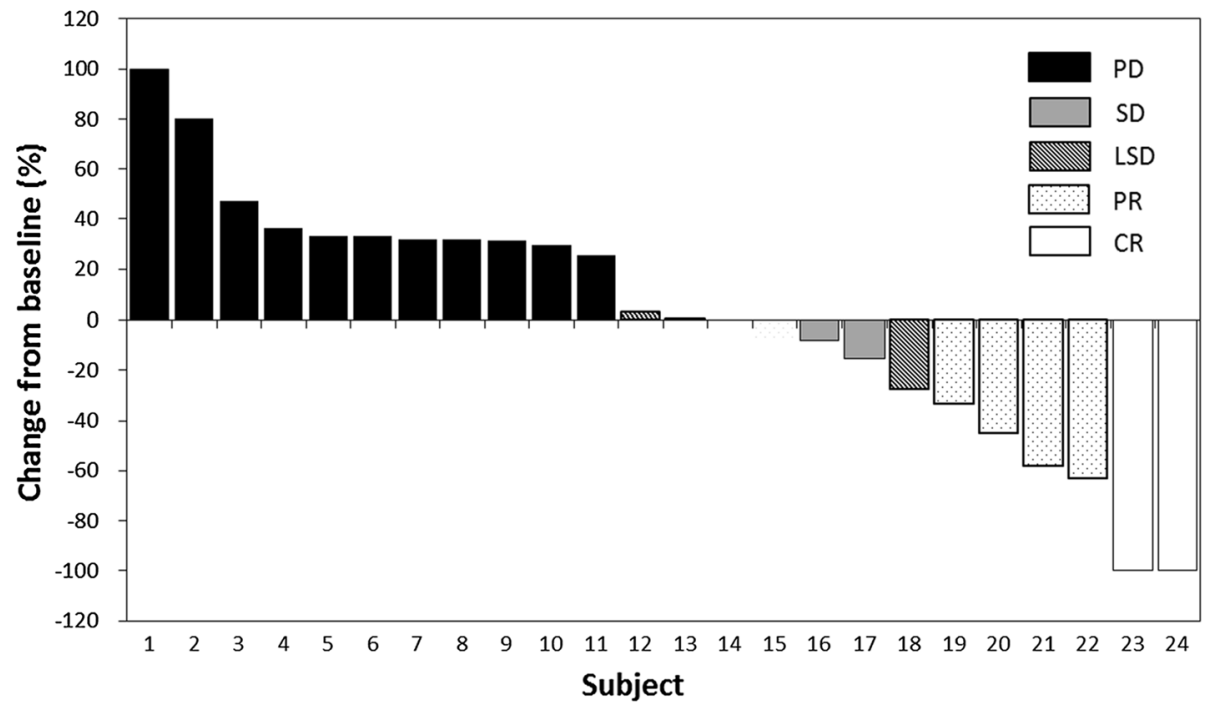

Panel C

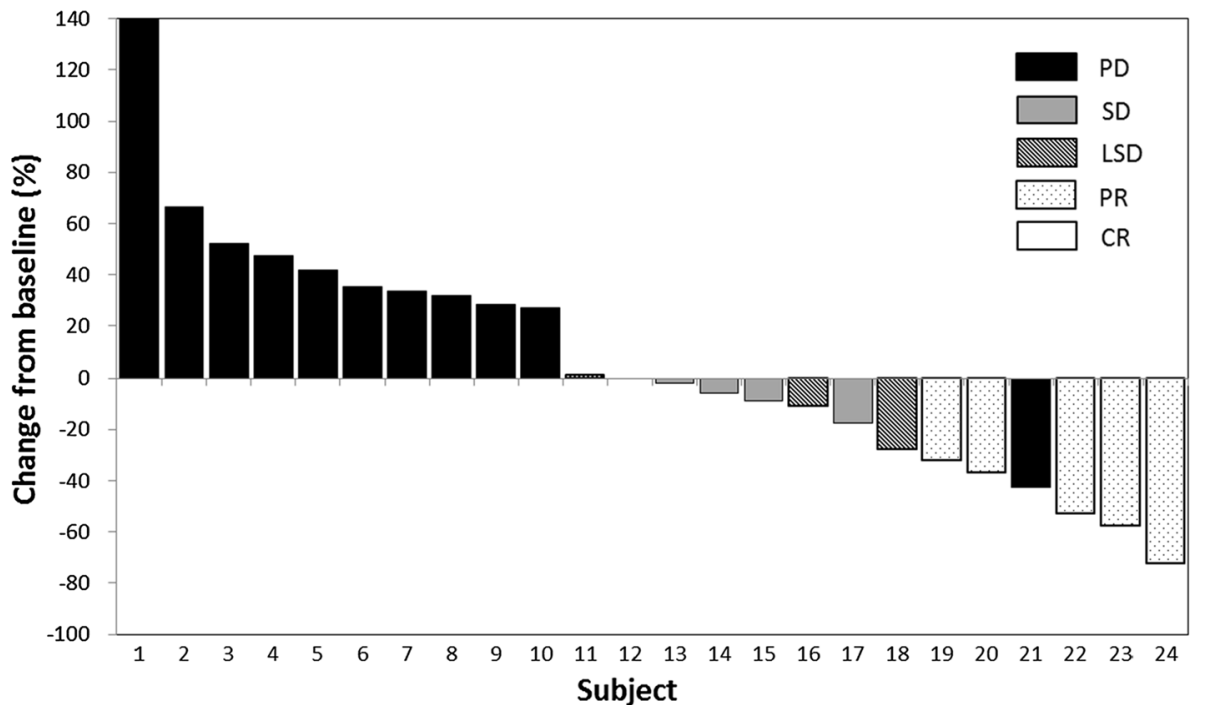


Table 3 Best overall tumor responses by receptor status

\begin{tabular}{|c|c|c|c|}
\hline & \multicolumn{3}{|l|}{ Receptor status } \\
\hline & ER-positive $(n=31,60.7 \%)$ & Triple-negative $(n=19,37.3 \%)$ & Unknown $(n=1,2.0 \%)$ \\
\hline $\mathrm{CR}$ & $0(0 \%)$ & $1(5.3 \%)$ & $0(0 \%)$ \\
\hline PR & $7(22.6 \%)$ & $5(26.3 \%)$ & $0(0 \%)$ \\
\hline LSD & $4(12.9 \%)$ & $2(10.5 \%)$ & $1(100 \%)$ \\
\hline SD & $5(16.1 \%)$ & $0(0 \%)$ & $0(0 \%)$ \\
\hline $\mathrm{PD}$ & $14(45.2 \%)$ & $11(57.9 \%)$ & $0(0 \%)$ \\
\hline $\mathrm{NE}$ & $1(3.2 \%)$ & $0(0 \%)$ & $0(0 \%)$ \\
\hline Clinical benefit rate $(\mathrm{CR}+\mathrm{PR}+\mathrm{LSD})$ & $11(35.5 \%)$ & $8(42.1 \%)$ & $1(100 \%)$ \\
\hline $95 \% \mathrm{CI}$ & $19.2-54.6$ & $20.3-66.5$ & \\
\hline Overall response rate $(\mathrm{CR}+\mathrm{PR})$ & $7(22.6 \%)$ & $6(31.6 \%)$ & $0(0 \%)$ \\
\hline $95 \% \mathrm{CI}$ & $9.6-41.1$ & $12.6-56.6$ & \\
\hline Disease control rate $(\mathrm{CR}+\mathrm{PR}+\mathrm{SD})$ & $16(51.6 \%)$ & $8(42.1 \%)$ & $1(100 \%)$ \\
\hline $95 \% \mathrm{CI}$ & $33.1-69.9$ & $20.3-66.5$ & \\
\hline
\end{tabular}

$C R$ complete response, $P R$ partial response, $L S D$ long-term stable disease $\geq 24$ weeks, $S D$ stable disease, $P D$ progressive disease, $N E$ not evaluable

Table 4 Best overall responses by organ

\begin{tabular}{|c|c|c|c|c|}
\hline Site of metastasis & $N$ & CBR $n$ (percentage) & ORR $n$ (percentage) & DCR $n$ (percentage) \\
\hline Local lesion & 15 & $3(20.0 \%)$ & $3(20.0 \%)$ & $7(46.7 \%)$ \\
\hline $95 \% \mathrm{CI}$ & & $4.3-48.1$ & $4.3-48.1$ & $21.3-73.4$ \\
\hline Regional lymph node & 18 & $8(44.4 \%)$ & $5(27.8 \%)$ & $11(61.1 \%)$ \\
\hline $95 \% \mathrm{CI}$ & & $21.5-69.2$ & $9.7-53.5$ & $35.8-82.7$ \\
\hline Distal lymph node & 20 & $6(30.0 \%)$ & $4(20.0 \%)$ & $12(60.0 \%)$ \\
\hline $95 \% \mathrm{CI}$ & & $11.9-54.3$ & $5.7-43.7$ & $36.1-80.9$ \\
\hline Bone & 28 & $5(17.9 \%)$ & $0(0.0 \%)$ & $17(60.7 \%)$ \\
\hline $95 \% \mathrm{CI}$ & & $6.1-36.9$ & & $40.6-78.5$ \\
\hline Lung & 24 & $10(41.7 \%)$ & $6(25.0 \%)$ & $13(54.2 \%)$ \\
\hline $95 \% \mathrm{CI}$ & & $22.1-63.4$ & $9.8-46.7$ & $32.8-74.5$ \\
\hline Pleura/pleural effusion & 10 & $4(40.0 \%)$ & $2(20.0 \%)$ & $7(70.0 \%)$ \\
\hline $95 \% \mathrm{CI}$ & & $12.1-73.8$ & $2.5-55.6$ & $34.8-93.3$ \\
\hline Liver & 25 & $10(40.0 \%)$ & $6(24.0 \%)$ & $14(56.0 \%)$ \\
\hline $95 \% \mathrm{CI}$ & & $21.1-61.3$ & $9.4-45.1$ & $34.9-75.6$ \\
\hline Brain & 3 & $1(33.3 \%)$ & $0(0.0 \%)$ & $2(66.7 \%)$ \\
\hline
\end{tabular}

dose interruptions/delays or dose reductions, or with G-CSFs, administered to 4 patients $(7.8 \%)$. Dose interruptions were caused most frequently by neutropenia, peripheral neuropathy, ALT increased, and pulmonary fibrosis (10, 1, 1, and 1 patients, respectively). On the other hand, dose reductions were required most frequently by neutropenia, peripheral neuropathy, and ALT increased (9, 1 , and 1 patients, respectively). Furthermore, dose delays were necessitated most frequently by neutropenia, peripheral neuropathy, and others (10, 4, and 4, respectively). The incidence of grade 3 peripheral sensory neuropathy was
$2.0 \%(1 / 51)$, and neither grade 3 motor neuropathy nor grade 4 peripheral sensory/motor neuropathy was observed.

\section{Discussion}

In EMBRACE Study [25] that examined patients who had undergone anthracycline- and taxane-based treatment for locally recurrent breast cancer or MBC, the median OS was 13.1 months for eribulin monotherapy and 10.6 months for 
Table 5 Best overall responses by prior taxane treatment

\begin{tabular}{lcccc}
\hline Prior taxane treatment & $N$ & CBR $n$ (percentage) & ORR $n$ (percentage) & DCR $n$ (percentage) \\
\hline Paclitaxel & 42 & $15(35.7 \%)$ & $10(23.8 \%)$ & $19(45.2 \%)$ \\
$95 \% \mathrm{CI}$ & & $21.6-52.0$ & $12.1-39.5$ & $30.0-61.3$ \\
Docetaxel & 8 & $4(50.0 \%)$ & $3(37.5 \%)$ & $5(62.5 \%)$ \\
$95 \% \mathrm{CI}$ & & $15.7-84.3$ & $8.5-75.5$ & $24.5-91.5$ \\
Paclitaxel + docetaxel & 1 & $1(100.0 \%)$ & $0(0 \%)$ & $1(100.0 \%)$ \\
\hline
\end{tabular}

ORR overall response rate $(\mathrm{CR}+\mathrm{PR}), C R$ complete response, $P R$ partial response, $C B R$ $(\mathrm{CR}+\mathrm{PR}+\mathrm{LSD})$ clinical benefit rate, $L S D$ long-term stable disease $\geq 24$ weeks, $D C R$ disease control rate $(\mathrm{CR}+\mathrm{PR}+\mathrm{SD}), S D$ stable disease

Table 6 Best overall responses by taxane resistance pattern

\begin{tabular}{|c|c|c|c|c|}
\hline \multirow[t]{2}{*}{ Well-defined taxane resistance $^{\dagger}$ pattern } & \multirow[t]{2}{*}{$N=51$} & \multicolumn{3}{|c|}{ Variables for efficacy } \\
\hline & & CBR & ORR & DCR \\
\hline Neoadjuvant chemotherapy for PD, $n(\%)$ & 2 & $1(50.0 \%)$ & $1(50.0 \%)$ & $1(50.0 \%)$ \\
\hline $\begin{array}{l}\text { Chemotherapy for metastasis within } 1 \text { year after the last } \\
\text { administration of taxane, } n(\%)\end{array}$ & 7 & $3(42.9 \%)$ & $2(28.6 \%)$ & $4(57.1 \%)$ \\
\hline $95 \% \mathrm{CI}$ & & $9.9-81.6$ & $3.7-71.0$ & 18.4-90.1 \\
\hline Adjuvant therapy & 2 & $1(50.0 \%)$ & $1(50.0 \%)$ & $1(50.0 \%)$ \\
\hline Neoadjuvant therapy & 5 & $2(40.0 \%)$ & $1(20.0 \%)$ & $3(60.0 \%)$ \\
\hline \multicolumn{5}{|l|}{ Tumor progression, $n(\%)$} \\
\hline $\mathrm{PR}$ to $\mathrm{PD}$ & 17 & $4(23.5 \%)$ & $3(17.6 \%)$ & $6(35.3 \%)$ \\
\hline $95 \% \mathrm{CI}$ & & $6.8-49.9$ & $3.8-43.4$ & $14.2-61.7$ \\
\hline $\mathrm{SD}$ to $\mathrm{PD}$ & 14 & $7(50.0 \%)$ & $4(28.6 \%)$ & $8(57.1 \%)$ \\
\hline $95 \% \mathrm{CI}$ & & $23.0-77.0$ & $8.4-58.1$ & $28.9-82.3$ \\
\hline PD & 11 & $3(27.3 \%)$ & $3(27.3 \%)$ & $3(27.3 \%)$ \\
\hline $95 \%$ CI & & $6.0-61.0$ & $6.0-61.0$ & $6.0-61.0$ \\
\hline
\end{tabular}

$C B R$ clinical benefit rate (CR + PR + LSD), $C R$ complete response, $P R$ partial response, $L S D$ long-term stable disease $\geq 24$ weeks, $O R R$ overall response rate $(\mathrm{CR}+\mathrm{PR}), D C R$ disease control rate $(\mathrm{CR}+\mathrm{PR}+\mathrm{SD})$

$\dagger$ Defined as "tumor metastasis during taxane treatment or within 1 year after the last administration of a taxane" or "tumor progress (from CR/ PR/SD to PD) during taxane treatment."

No patient with CR in our study

TPC; eribulin thus indicated a 2.5 -month extension of the median OS in patients who were taxane refractory because of having shown disease progression within 6 months of latest chemotherapy. In view of the outcomes from the EMBRACE Study, we intended to examine the efficacy and safety of eribulin monotherapy in Japanese female patients with MBC who had stricter taxane resistance (tumor progression within 1 year after treatment with taxanes) than the study.

Our study population consisted of heavily pretreated patients, the majority of whom $(76.5 \%)$ already had three or more sites of metastasis at baseline. Despite these facts, a certain level of anticancer activity was observed in our patients who had stricter taxane resistance than that in the study conducted by Aogi et al. [24]. After excluding six patients who had not received anthracyclines, the activity was demonstrated with a CBR of $35.6 \%$ (vs. $27.5 \%$ ), a median ORR of $24.4 \%$ (vs. $21.3 \%$ ), a median PFS of 3.5 months (vs. 3.7 months), and a median OS of 11.7 months (vs. 11.1 months). Compared with their study, namely, the efficacy profile of eribulin was better and equivalent with respect to variables for efficacy including the CBR.

Furthermore, the CBR in the present study was equivalent to the CBRs (17.1-32.9\%) described in other prior Phase II and III clinical studies of eribulin monotherapy in non-Japanese patients [20, 21, 25, 26]; however, the CBR in our study was much lower than 51.8 and $62.9 \%$ in Phase II clinical studies of eribulin as first-line therapy conducted by McIntyre et al. [22] and Takashima et al. [23] - a sufficiently comprehensible fact when considering differences between the first- and late-line therapies. The median ORR in the present study was equivalent to $21.3 \%$ [24] in Japanese patients and was higher than 9.3-16.1\% 
Table 7 Most common adverse events with an incidence of $\geq 10 \%$ for all grades by CTCAE grade in the safety population $(n=51)$

\begin{tabular}{lccccc}
\hline Adverse event & Severity & & & \\
\cline { 2 - 5 } & All grades & Grade 1 & Grade 2 & Grade 3 & Grade 4 \\
\hline Hematologic & & & & & \\
Neutropenia & $29(56.9 \%)$ & $1(2.0 \%)$ & $10(19.6 \%)$ & $9(17.6 \%)$ & $9(17.6 \%)$ \\
Leukopenia & $30(58,8 \%)$ & $5(9.8 \%)$ & $13(25.5 \%)$ & $10(19.6 \%)$ & $2(3.9 \%)$ \\
Anemia & $15(29.4 \%)$ & $10(19.6 \%)$ & $2(3.9 \%)$ & $3(5.9 \%)$ & \\
Febrile neutropenia & $4(7.8 \%)$ & & & $4(7.8 \%)$ & \\
Thrombocytopenia & $2(3.9 \%)$ & $1(2.0 \%)$ & $1(2.0 \%)$ & & \\
Nonhematologic & & & & & \\
Oral mucositis & $7(13.7 \%)$ & $7(13.7 \%)$ & & \\
Alopecia & $7(13.7 \%)$ & $6(11.8 \%)$ & $1(2.0 \%)$ & \\
AST increased & $7(13.7 \%)$ & $6(11.8 \%)$ & $1(2.0 \%)$ & \\
Fatigue & $7(13.7 \%)$ & $4(7.8 \%)$ & $2(3.9 \%)$ & $1(2.0 \%)$ & \\
Constipation & $7(13.7 \%)$ & $4(7.8 \%)$ & $3(5.9 \%)$ & & \\
Anorexia & $7(13.7 \%)$ & $5(9.8 \%)$ & $2(3.9 \%)$ & \\
Peripheral motor neuropathy & $7(13.7 \%)$ & $7(13.7 \%)$ & & \\
Nausea & $6(11.8 \%)$ & $5(9.8 \%)$ & $1(2.0 \%)$ & \\
Peripheral sensory neuropathy & $6(11.8 \%)$ & $2(3.9 \%)$ & $3(5.9 \%)$ & $1(2.0 \%)$ & \\
ALT increased & $5(9.8 \%)$ & $3(5.9 \%)$ & & $2(3.9 \%)$ \\
Diarrhea & $4(7.8 \%)$ & $2(3.9 \%)$ & $2(3.9 \%)$ & \\
\hline
\end{tabular}

CTCAE common terminology criteria for adverse events, $A L T$ alanine aminotransferase, $A S T$ aspartate aminotransferase in non-Japanese patients [20-22, 25, 26]. In addition, the median PFS and the median OS in this study were comparable to 2.6-4.1 months and 9.2-15.9 months in nonJapanese patients, respectively [20-22, 25, 26].

The subgroup analyses of best overall responses revealed several novel insights into the efficacy profile of eribulin. The CBRs were comparable between the "ERpositive" and "triple-negative" categories in receptor status (Table 3); this might indicate that eribulin suppresses disease progression regardless of receptor status. The top three CBRs by organ in decreasing order were found for the regional lymph node $(44.4 \%)$, as well as for vital organs-lung $(41.7 \%)$ and liver (40.0\%) (Table 4) (Fig. 2). Namely, eribulin showed efficacy in nonvisceral and visceral organs as with the study conducted by Aogi et al. The waterfall plot analysis of maximal changes in metastatic tumor size by organ (Fig. 2, overall) revealed a markedly reduced proportion of patients who presented SD and LSD (23.5\%) as compared with $37.5 \%$ in the study conducted by Aogi et al. Namely, our study suggested cross resistance in a proportion of the enrolled patients. On the other hand, eribulin also showed the ORR comparable to that in the study conducted by Aogi et al. in Japanese patients with MBC, thus possibly reflecting the preclinical evidence that eribulin has antitumor activity against taxane-resistant tumor cell lines [13]. Eribulin showed efficacy regardless of a difference in taxanes-paclitaxel and docetaxel (Table 5). In addition, the subgroup analysis of best overall responses by well-defined taxane resistance pattern in our patients revealed the following findings of interest (Table 6): (1) the predominant (about $80 \%$ ) pathogenesis of taxane resistance was tumor progression; (2) all subgroups of tumor progression patterns showed the CBRs of $\geq 20 \%$, i.e., eribulin provided a given level of tumor response regardless of taxane resistance pattern; and (3) the CBR was higher in patients whose tumor progression shifted from "SD" to "PD" than in those from "PR" to "SD" or whose tumor exhibited "PD." Nevertheless, further study will be required to specify the factors involved in these findings through the acquisition of information on exposure to taxanes in prior chemotherapy regimens and others.

The safety profile of eribulin in the present study is in line with what has been described in the previous Phase II and III clinical trials of eribulin monotherapy [20-26]. Concretely, leukopenia (58.8\%), neutropenia (56.9\%), and anemia (29.4\%) constituted major hematologic AEs as with the clinical trials conducted by Aogi et al., Cortes et al., and Kahfman et al. AEs requiring dose modifications were grade 3 febrile neutropenia and grade 4 neutropenia, the incidences of which in the present study were comparable to or lower than those described in the abovementioned studies which ranged between 25.0 and $95.1 \%$ and between 21.0 and $24.6 \%$, respectively. Importantly, 
eribulin indicated an incidence of grade 3 febrile neutropenia $(7.8 \%)$, which was much lower than $13.6 \%$ in Japanese patients [24] and was comparable to $2.0-5.5 \%$ in non-Japanese patients [20-22, 25, 26]. Both grade 3 febrile neutropenia and grade 4 neutropenia were successfully managed by dose modifications or with G-CSFs. Of note were the following facts: (1) the incidences of grade 1 peripheral neuropathy and grade 3 peripheral sensory neuropathy were as low as 13.7 and $2.0 \%$, respectively; and (2) grade 4 peripheral motor/sensory neuropathy did not develop as with the studies conducted by Vahdat et al., Cortes et al., and McIntyre et al. [20-22].

Apart from the clinical benefits of eribulin monotherapy described above, eribulin also offers therapeutic advantages because of necessitating an intravenous infusion time that is as short as $2-5 \mathrm{~min}$, requiring no premedication to prevent hypersensitivity, and causing little infusion-related reactions during repeated administration.

\section{Study limitations}

The present study had several limitations. First, sample size is relatively small. However, our study provided the efficacy and safety profiles of eribulin monotherapy that were in accord with those described in a previous clinical study in Japanese patients with heavily pretreated MBC. Second, our study is not a randomized clinical study, thus affording practical insights of lower evidence level but reflecting the real-world clinical settings. Third, we could not obtain detailed information on the factors of prior chemotherapy regimens that might influence disease progression after the onset of eribulin monotherapy. The acquisition of the relevant information and the accumulation of new patients will help specify MBC patients presenting well-defined taxane resistance to whom eribulin is expected to be most effective.

\section{Conclusions}

Eribulin was effective for heavily pretreated patients with MBC who were found to have well-defined taxane resistance. Furthermore, eribulin exhibited the clinically manageable safety profile in the study population including patients with MBC who developed peripheral neuropathy. Together, eribulin is a potential therapeutic option in the clinical settings.

Acknowledgments The authors thank Satoshi Sakima, MD, for his gracious review of the manuscript and Ms. Masako Nakamura for her technical assistance. The present study was supported by the National Cancer Center Research and Development Fund (23-A-16, 23-A-17, 26-A-4) and Health and Labour Sciences Research Expenses for Commission, Applied Research for Innovative Treatment of Cancer from the Ministry of Health, Labour and Welfare (H26-applied-general-043,046). Furthermore, this research was supported by the Practical Research for Innovative Cancer Control (15ck0106046h0002, 15ck0106049h0002) from Japan Agency for Medical Research and Development, AMED and by Saitama Breast Cancer Clinical Study Group (24). Medical writing was funded by Eisai Co., Ltd.

Author Contributions KI conceived the study, participated in the design, and drafted the manuscript. KI, KK, and HY conducted the data analysis. KI, TS, KO, KK, HY, TS, KI, and SH played a significant role in the acquisition and interpretation of data and in the critical revision of the manuscript for important intellectual content. All authors read and approved the final manuscript.

\section{Compliance with ethical standards}

Conflict of interest KI received lecture free from Eisai Co., Ltd. Other authors declare that they have no conflict of interest.

Open Access This article is distributed under the terms of the Creative Commons Attribution-NonCommercial 4.0 International License (http://creativecommons.org/licenses/by-nc/4.0/), which permits any noncommercial use, distribution, and reproduction in any medium, provided you give appropriate credit to the original author(s) and the source, provide a link to the Creative Commons license, and indicate if changes were made.

\section{References}

1. Siegel RL, Miller KD, Jemal A (2015) Cancer statistics 2015. CA Cancer J Clin 65(1):5-29

2. Cardoso F, Harbeck N, Fallowfield L, Kyriakides S, Senkus E, ESMO Guidelines Working Group (2012) Locally recurrent or metastatic breast cancer: ESMO clinical practice guidelines for diagnosis, treatment and follow-up. Ann Oncol 23(Suppl 7):vii11-vii19

3. Cancer Statistics in Japan (2014) Foundation for promotion of cancer research. http://ganjoho.jp/en/professional/statistics/bro chure/2014_en.html. Accessed 28 Feb 2015

4. National Comprehensive Cancer Network (2015) NCCN clinical practice guidelines in oncology $\left(\mathrm{NCCN}\right.$ guideline ${ }^{\circledR}$ : breast cancer version 2.2015. National comprehensive cancer network, Fort Washington. http://www.nccn.org/professionals/default.aspx. Accessed 20 Dec 2015

5. Zhixiang Wang Z (2014) Taxane resistance in breast cancer. Cancer Cell Microenviron 1:e126

6. Pean E, Klaar S, Berglund EG, Salmonson T, Borregaard J, Hofland KF, Ersbøll J, Abadie E, Giuliani R, Pignatti F (2012) The European medicines agency review of eribulin for the treatment of patients with locally advanced or metastatic breast cancer: summary of the scientific assessment of the committee for medicinal products for human use. Clin Cancer Res 18(17):4491-4497

7. Jordan MA, Kamath K, Manna T, Okouneva T, Miller HP, Davis C, Littlefield BA, Wilson L (2005) The primary antimitotic mechanism of action of the synthetic halichondrin E7389 is suppression of microtubule growth. Mol Cancer Ther 4(7):1086-1095

8. Smith JA, Wilson L, Azarenko O, Zhu X, Lewis BM, Littlefield BA, Jordan MA (2010) Eribulin binds at microtubule ends to a single site on tubulin to suppress dynamic instability. Biochemistry 49(6):1331-1337

9. Towle MJ, Salvato KA, Budrow J, Wels BF, Kuznetsov G, Aalfs KK, Welsh S, Zheng W, Seletsky BM, Palme MH et al (2001) 
In vitro and in vivo anticancer activities of synthetic macrocyclic ketone analogues of halichondrin B. Cancer Res 61(3):1013-1021

10. Kuznetsov G, Towle MJ, Cheng H, Kawamura T, TenDyke K, Liu D, Kishi Y, Yu MJ, Littlefield BA et al (2004) Induction of morphological and biochemical apoptosis following prolonged mitotic blockage by halichondrin $\mathrm{B}$ macrocyclic ketone analog E7389. Cancer Res 64(16):5760-5766

11. Okouneva T, Azarenko O, Wilson I, Littlefield BA, Jordan MA (2008) Inhibition of centromere dynamics by eribulin (E7389) during mitotic metaphase. Mol Cancer Ther 7(7):2003-2011

12. Towle MJ, Nomoto K, Asano M, Kishi Y, Yu MJ, Littlefield BA (2012) Broad spectrum preclinical antitumor activity of eribulin (Halaven(R)): optimal effectiveness under intermittent dosing conditions. Anticancer Res 32(5):1611-1619

13. Kuznetsov G, TenDyke K, Yu M, Littlefield B (2007) Antiproliferative effects of halichondron $\mathrm{B}$ analog eribulin mesylate (E7389) against paclitaxel-resistant human cell lines in vitro. AACR-NCI-EORTC international conference: molecular targets and cancer therapeutics-Oct 22-26, 2007, San Francisco, CA

14. Funahashi Y, Okamoto K, Adachi Y, Semba T, Uesugi M, Ozawa Y, Tohyama O, Uehara T, Kimura T, Watanabe H et al (2014) Eribulin mesylate reduces tumor microenvironment abnormality by vascular remodeling in preclinical human breast cancer models. Cancer Sci 105(10):1334-1342

15. Gavert N, Ben-Ze'ev A (2008) Epithelial-mesenchymal transition and the invasive potential of tumors. Trends Mol Med 14(5):199-209

16. Polyak K, Weinberg RA (2009) Transitions between epithelial and mesenchymal states: acquisition of malignant and stem cell traits. Nat Rev Cancer 9(4):265-273

17. Gunasinghe NP, Wells A, Thompson EW, Hugo HJ (2012) Mesenchymal-epithelial transition (MET) as a mechanism for metastatic colonization in breast cancer. Cancer Metastasis Rev 31(3-4):469-478

18. Yoshida T, Ozawa Y, Kimura T, Sato Y, Kuznetsov G, Xu S, Uesugi M, Agoulnik S, Taylor N, Funahashi Y et al (2014) Eribulin mesilate suppresses experimental metastasis of breast cancer cells by reversing phenotype from epithelial-mesenchymal transition (EMT) to mesenchymal-epithelial transition (MET) states. Br J Cancer 110(6):1497-1505

19. Dezső Z, Oestreicher J, Weaver A, Santiago S, Agoulnik S, Chow J, Oda Y, Funahashi Y (2014) Gene expression profiling reveals epithelial mesenchymal transition (EMT) genes can selectively differentiate eribulin sensitive breast cancer cells. PLoS One 9(8):e106131
20. Vahdat LT, Pruitt B, Fabian CJ, Rivera RR, Smith DA, Tan-Chiu E, Wright J, Tan AR, Dacosta NA, Chuang E et al (2009) Phase II study of eribulin mesylate, a halichondrin B analog, in patients with metastatic breast cancer previously treated with an anthracycline and a taxane. J Clin Oncol 27(18):2954-2961

21. Cortes J, Vahdat L, Blum JL, Twelves C, Campone M, Roché H, Bachelot T, Awada A, Paridaens R, Goncalves A et al (2010) Phase II study of the halichondrin B analog eribulin in patients with locally advanced or metastatic breast cancer previously treated with an anthracycline, a taxane, and capecitabine. J Clin Oncol 28(25):3922-3928

22. McIntyre K, O’Shaughnessy J, Schwartzberg L, Glück S, Berrak E, Song JX, Cox D, Vahdat LT (2014) Phase II study of eribulin mesylate as first-line therapy for locally recurrent or metastatic human epidermal growth factor receptor 2-negative breast cancer. Breast Cancer Res Treat 146(2):321-328

23. Takashima $T$, Tokunaga $S$, Tei S, Nishimura S, Kawajiri H, Kashiwagi S, Yamagata S, Noda S, Nishimori T, Mizuyama Y et al (2016) A phase II, multicenter, single-arm trial of eribulin as first-line chemotherapy for HER2-negative locally advanced or metastatic breast cancer. SpringerPlus 5:164

24. Aogi K, Iwata H, Masuda N, Mukai H, Yoshida M, Rai Y, Taguchi K, Sasaki Y, Takashima S (2011) A phase II study of eribulin in Japanese patients with heavily pretreated metastatic breast cancer. Ann Oncol 23(6):1441-1448

25. Cortes J, O'Shaughnessy J, Loesch D, Blum JL, Vahdat LT, Petrakova K, Chollet P, Manikas A, Diéras V, Delozier T et al (2011) Eribulin monotherapy versus treatment of physician's choice in patients with metastatic breast cancer (EMBRACE): a phase 3 open-label randomized study. Lancet 377(9769):914-923

26. Kaufman PA, Awada A, Twelves C, Yelle L, Perez EA, Velikova G, Olivo MS, He Y, Dutcus CE, Cortes J (2015) Phase III openlabel randomized study of eribulin mesylate versus capecitabine in patients with locally advanced or metastatic breast cancer previously treated with an anthracycline and a taxane. J Clin Oncol 33(6):594-601

27. Jain S, Cigler T (2012) Eribulin mesylate in the treatment of metastatic breast cancer. Biologics 6:21-29

28. Eisenhauer EA, Therasse P, Bogaerts J, Schwartz LH, Sargent D, Ford R, Dancey J, Arbuck S, Gwyther S, Mooney M et al (2009) New response evaluation criteria in solid tumors: revised RECIST guideline (version 1.1). Eur J Cancer 45(2):228-247 